\title{
O SER AÍ OU A CONTINGÊNCIA NA OBRA DE TABUCCHI HIPÓTESE PARA UMA LEITURA VITIMAL
}

Glauber Rezende Jacob Willrich

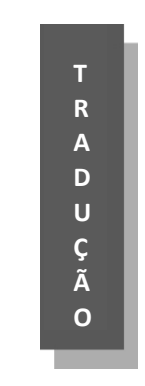

Tradução do artigo intitulado L'être-là ou la contingence dans l'oeuvre de Tabucchi, de Gerard Vittori, niversité Rennes 2 - Haute Bretagne, realizada como atividade complementar no programa de pós-graduação em Letras da Universidade Federal do Paraná.

Todo leitor das obras de Tabucchi já teria feito a constatação de um certo interesse deste autor pela filosofia que se manifesta sob a forma do que podemos chamar de traços: os filósofos como Platão, Aristóteles ou Descartes são citados ou mencionados através da adjetivação de alguns substantivos; aqui ou ali aparecem alusões ${ }^{1}$, ou, mais diretamente, expressões tais como a ideia platônica ${ }^{2}$ ou lógica aristotélico-cartesiana; e nos é preciso igualmente citar o nome do protagonista do Fio do Horizonte, Spino, que é uma referência quase explícita à filosofia de Espinosa. Esta não transforma nenhuma obra de Tabucchi em obra filosófica, mas simplesmente mostra, no seio mesmo da obra literária, a presença de uma reflexão que não rompeu todas as linhas com a tradição metafísica, talvez simplesmente porque a modernidade não pode necessariamente fazer vista grossa a tudo que a precedeu, e também ela não pode se distanciar ou descartar não deixando de lhe fazer referência. Para além dessa consideração, os índices que mencionamos anteriormente mostram a presença e a efetividade de uma reflexão que por tomar (ou imaginar e inventar) a experiência a compreende sob um ângulo novo, se servindo de instrumentos que a tradição cultural lhe legou.

Essa presença da referência filosófica poderia convidar a pensar que existe no universo de Tabucchi uma organização do mundo a partir de uma centralidade, a partir de um princípio unificador que dá conta da totalidade dos fenômenos, assim como os diferentes aspectos, concretos, da existência. Pelo

\footnotetext{
${ }^{1}$ Em Pequenos equívocos sem importância, Milão, Feltrinelli, 2006 [1985], p. 96, em O Rancor e o novo encontramos uma referência ao platonismo e ao logos metafísico que atravessa as páginas de algumas críticas literárias. $O$ advogado Loton em $A$ cabeça perdida de Damasceno Monteiro faz numerosas alusões ou referência à filosofia (entre outras à de Rudolf Carnap). Ao fim do romance $O$ pequeno navio, aparece um personagem denominado Sócrates, que se conhecia bem a si mesmo. Enfim - mas a lista não é completa - a carta intitulada Fiume em Se está fazendo sempre tão tarde é uma alusão direta a Plotin, como o próprio Tabucchi confirma: "Lendo Plotin [que, de qualquer modo, é igualmente citado em uma nota final], encontramos que a vida é ao mesmo tempo princípio e ausência, emanação primordial e impossibilidade de determinação mensurável. Em suma, é um rio sem bancos", Autobiografia Altrui, Milão, Feltrinelli, 2003, p. 86.

2 "uma espécie de ideia platônica de Café", Se está fazendo sempre tão tarde, Milão, Feltrinelli, 2006 [2001], p. 49.
} 
contrário, se existe mesmo uma reflexão das diferentes personagens da obra sobre a experiência de cada dia, essa reflexão que, certamente sintetiza a experiência para lhe sublinhar os traços característicos, insiste e mesmo confina sobre a realidade das coisas que consiste nisso que o ser humano é livre na contingência das formas: contingência dos corpos, contingência das circunstâncias que, no entanto, deixam um traço, deixam seu traço sobre o destino de cada um. É essa contingência que proporemos interrogar, uma contingência que não será somente um dado massivo no qual bastaria fazer a constatação e o inventário, mas sim uma contingência que permanece problemática, porque nela se trama, a todo instante, a tensão entre idealidade e materialidade. Porém, essa idealidade não se dá como realidade, ela aparece somente sob a forma de uma tendência, de uma aspiração, ou, evidentemente, de uma nostalgia, já que a materialidade, ela mesma, impõe sua realidade que tentamos fazer aparecer como realidade parcial, marcada por uma forma nativa de incompletude onde o trato dominante é o fragmento.

A contingência, e de maneira paradoxal, não se livra no imediato da experiência, mesmo se ela é essa imediatalidade sem cessar renovada; ela aparece somente na mediação de um retorno sobre os dados imediatos que é o ambiente cotidiano de cada um desde seu nascimento: "ela me pegava a mão e me dizia: escuta, que saibamos o que somos, que saiba onde estamos, que saiba porque nós estamos aqui..."3. O questionamento da personagem (Maria do Carmo Meneses) solicita os elementos mais óbvios da existência, nos aspectos mais simples e mais concretos. O elemento da contingência que, normalmente, se presta mesmo a uma interrogação qualquer, é este lugar: o lugar é a coisa que vai de si, ele se impõe em sua exterioridade absoluta como realidade no seio mesmo daquela que o sujeito se compreende. Se há qualquer coisa que parece dotada de uma incontestável evidência, é bem mesmo o lugar, o lugar onde estamos, o lugar onde se passa nossa existência, o lugar onde nosso corpo vive sua existência da carne. Interrogar o lugar, lhe questionar justamente em sua significação - exceto em sua simples denominação que não diz nada, é encontrar a ausência de significação, é o ser confrontado depois de ter questionado o que vai mais naturalmente de si. Subitamente, quando fazemos destacar a não-significação do lugar, este nos aparece em sua nudez absoluta, em sua pura materialidade: uma materialidade na qual o sujeito não pode se reconhecer, e que o faz se perceber, então, na pura contingência a qual ele é entregue. Subitamente, o lugar não é revestido de nenhuma essencialidade, e ele se torna absolutamente intercambiável: "Eu estou aqui como eu poderia estar em outro lugar"4. A experiência da contingência é antes de tudo a consciência da contingência, e ela significa uma espécie de equivalência generalizada ou generalizável: nenhuma necessidade

${ }^{3}$ O Jogo do Reverso e outros contos, Milão, Feltrinelli, 2006 [Milão, il Saggiatore, 1981, "Biblioteca delle Silerchie 8", depois, sob o título: O jogo do Reverso e outros contos, Milão, Feltrinelli, 1988], p. 17.

${ }^{4}$ Anywhere out of the wolrd em Pequenos equívocos sem importância, cit., p. 72. 
intrínseca não liga o sujeito ao lugar no qual ele se encontra e onde ele toma consciência de seu ser aí, e aqui é idêntico a outro lugar; a única coisa que distingue um de outro é a proximidade em relação ao sujeito. Mais potencialmente ("eu poderia estar"), aqui equivale a estar em outro lugar, e a única distinção entre eles é o agora: um ou outro podem se realizar apenas no tempo, portanto em momentos sucessivos. Se o lugar é em si indiferente e inessencial, uma coisa permanece, a necessidade de um lugar, ao mesmo tempo que sua unicidade: tal é a primeira forma de contingência.

O lugar é a condição mesma da materialidade, a materialidade é, por seu turno, a condição de toda existência. "No abstrato, não existimos", escreve Pirandello, mesmo se é no abstrato que falamos da existência e mesmo se a palavra existência é ela mesma uma abstração. A necessidade da materialidade é de qualquer forma transcrita de maneira divertida por Tabucchi no decorrer de um diálogo: "- Qual carro? - Este no qual supomos - Um carro qualquer - Ah não, não existe um carro qualquer. Os carros tem uma marca, uma cor, um cilindrado. Existem carros e carros. Escolha um."

É por um ato do pensamento que pode ser evocado "um carro qualquer"; a indeterminação é uma via do espírito que pode somente retornar às determinações concretas e necessariamente particulares. O "carro qualquer" não tem existência outra senão em sua representação mental: realidade para o espírito, mas não realidade enquanto não realizada nas formas concretas e por elas oferecidas à percepção.

O que vale para a ideia dos objetos inanimados vale a fortiori para os seres animados. As formas do corpo, da visão em particular, são compreendidas no seio de uma multiplicidade indistinta, onde as características individuais parecem se desfocar para deixar lugar a um "conjunto de indivíduos quaisquer": "eu sou uma visão anônima nessa loucura de visões anônimas"." Nada não identifica o sujeito de maneira significativa e sua individualidade não representa sua unicidade: ela é somente um indivíduo diante de uma loucura de indivíduos e ela manifesta somente o caráter comum de uma condição sine qua non partilhada por todos os seres (podemos dizer, por todos os estandos), a incontornável necessidade de formas contingentes. O corpo é, portanto, uma espécie de vetor da existência e ele veicula a realidade do ser, mas com sua contrapartida da materialidade indissociável da vida ela mesma: "Que idiotice estudar as estrelas, não? É para a terra que devemos olhar, pela terra, por que a vida nos obriga sempre a baixar a cabeça." Parece existir uma dissociação entre alma e corpo, entre espírito e corpo se preferirmos uma formulação menos engajada ideologicamente. A materialidade não é a orientação natural do espírito humano, e, entretanto, a ligação a essa materialidade é incessante se isto não é determinante. A contingência do ser aí é, a todo instante,

${ }^{5}$ O bater das asas de uma borboleta em Nova York pode provocar um tufão em Pequim? In Anjo Negro, Milão, Feltrinelli, 2007 [1991], p. 79.

${ }_{7}^{6}$ Pequenos equívocos sem importância, cit. p. 72.

${ }^{7}$ Se está fazendo sempre tão tarde, cit., p. 150. 
ultrapassada, já que o sujeito humano nunca está totalmente ali onde está seu corpo - ele está, de qualquer modo, sempre em movimento, em mudança para outro lugar - ele está sempre em outro lugar pelo pensamento, em outro lugar no tempo, passeando pelo passado e pelas lembranças do que não é mais, ou projetando para o futuro, com essa inacreditável capacidade de ultrapassar mesmo os limites de sua própria vida corporal ${ }^{8}$.

A materialidade não é somente aquela do corpo próprio, ela é também aquela de todos os corpos existentes, de todo objeto oferecido à percepção dos sentidos. A imediatalidade de sua compreensão não garante nenhuma "plausibilidade": os objetos parecem sempre demais, eles se dão em uma forma de opacidade à consciência, como sugere o protagonista da novela Esperando o inverno:

[...] A característica intolerável dos objetos que nos rodeiam, sua arrogância idiota e massiva que não pode prever as mudanças da vida e que vivem em sua impenetrável imanência, em uma materialidade flagrante e inocente, e por essa razão mesma, misteriosas. ${ }^{9}$

Os objetos são como "supérfluos", eles parecem constituir uma violação do espaço mental, pois eles são muito fortemente, de maneira muito flagrante, o que eles são; eles são quase "incongruentes" em sua realidade da matéria bruta, na essência que os constituem e que não podem nada significar para uma consciência humana. Sua inocência mesma parece ser uma testemunha de sua incongruência se seguimos com a associação que estabelece Tabucchi entre essas duas palavras ${ }^{10}$. Sua incongruência e também sua inocência são feitas de suas perfeitas identidades de si para si, da perfeita coincidência do que eles são com sua realidade, sem nenhuma mudança, sem nenhum "jogo" possível, em uma irremediável fixidez, que parece negar o movimento inerente a toda vida. No fundo, os objetos oferecem o espetáculo de sua plenitude, exceto se a plenitude não for recebida pela consciência, porque ela é ao mesmo tempo a opacidade das cosias.

O ser aí do homem é constituído na tensão, no entre-lugar da materialidade e da idealidade, isso é perceptível mesmo nas palavras, na diferença entre as palavras simplesmente concebidas e pensadas e as palavras escritas.

\footnotetext{
8 "[...] esses que imaginam mesmo de uma maneira bem vaga uma vida futura depois que as células e genomas que os tem em conjunto não se tornarão poeiras". O rio in Se está fazendo sempre tão tarde, cit., p. 31. Pereira também pensa na vida após a morte. Ou melhor ainda: "O futuro, o futuro! É nossa cultura, fundada sobre o que nós podemos ser, compreendeu Evangile [...]" Ibid.

${ }^{9}$ Esperando o inverno in Pequenos equívocos sem importância, cit., p. 19.

10 "[...] incongruentes e inocentes como são as mortes", Passado composto in As aves do Beato Angelico, Palerme, Sellerio, 2005 [1987], p. 25.
} 
Existiam somente de maneira aérea, ligeira, alada e misteriosa e livres de ser não estando, como o pensamento. E como eles se tornariam peremptórias aqui sobre o papel, e quase vulgares, com a irremediável arrogância das coisas que são. ${ }^{11}$

As palavras tem essa particularidade de participar do espírito como da matéria, e nelas se desenvolvem seu caractere propriamente humano tanto quanto a tensão que caracteriza o humano. Com o pensamento, no qual eles são o coração mesmo já que ele não é possível pensar sem as palavras que o dizem, eles partilham essa estranha modalidade de existência que consiste em poder ser não estando, o que assegura sua totalidade, sua radical liberdade. Ser não estando, isso significa ter uma forma de existência sem suportar a materialidade, sem ser alienado à materialidade. Eis que poderia ser finalmente o sonho de toda humanidade, uma espécie de existência de razão que não comporia com as formas restritas da matéria, com os pés da realidade física. Salvo que este tipo de existência só é possível para os objetos do pensamento, ele não é possível pelo sujeito do pensamento, que tem necessariamente uma restrição na materialidade, e que as palavras, a rigor, pudessem se dispensar de ter se seu enunciador e contentasse com a pura enunciação oral, ou melhor ainda, com o puro pensamento silencioso. ${ }^{12}$

A recusa da materialidade e de suas restrições encontra uma expressão divertida entre os personagens do romance $O$ pequeno navio: Leonido, com raiva das gruas e desejoso de poder voar como elas, diz, depois de ter feito um pouso quase mortal na pedreira de mármore onde ele trabalha: "Nosso pior destino, é a lei da gravidade. Para o momento."13 A lei da gravidade, que é a lei que se impõe a todos os seres, animados ou inanimados, é humoristicamente (da parte do autor, não do personagem) apresentada como um destino, quer dizer, como alguma coisa que advém, que não pode não advir (nisso efetivamente a lei física e o destino se confundem), mas que não teríamos podido conhecer antes que ela viesse (isso é vero para o destino, não para a lei da gravidade). O humor reside também no fato de que Leonido não tinha verdadeiramente compreendido a significação do que é uma lei, quando ele anuncia para o momento. Mas, se isso parece uma verdade de propósito deste personagem bastante "excêntrico", é isso que pode aparecer como uma lei humana em todo caso, a aspiração à idealidade - que toma aqui a forma de desejo de emancipação da lei da gravidade ${ }^{14}$.

\footnotetext{
${ }^{11}$ Livros nunca escritos, viagens nunca feitas, in Se está fazendo sempre tão tarde, cit., p. 146.

${ }^{12} \mathrm{~A}$ forma mais perfeita do suicídio seria o silêncio, porque ele é difícil de manter, em oposição ao gesto radical da supressão da vida. O silêncio tem como inimigo o tempo: "...ele afronta o dia-a-dia de nossa vida..." O rio in Se está fazendo sempre tão tarde, cit., p. 26-27.

${ }^{13}$ O pequeno navio, tradução do italiano por Lise Chapuis, Paris, Éditions du Seuil, 2000 [1979]. Coll. "points", p. 40-41 (II Piccolo naviglio, Milan, Mondadori, 1978, Coll "Scrittori italiani e stranieri", p. 32).

${ }^{14}$ Notemos o humor do texto: "[...] a Casa de Savoie faria igualmente justiça dessa lei, se se tratasse de uma lei injusta [...]". Ibid., p. 41 (1978, p. 32). O mesmo humor está presente na inscrição funerária: "gravitas me rapuit" (latim, eu peguei gravidade). Ibid., p. 47 (1978, p. 37).
} 
É sempre próximo da morte, à margem da vida, que podemos compreender de maneira mais visível ainda essa idealidade constitutiva do ser humano: a propósito do suicídio (em ocorrência do suicídio pelo salto no vazio), Tabucchi escreve: "o salto faz parte do voo, ele contém uma espécie de rebeldia contra a condição humana do bípede, ele vai para o espaço, às grandes dimensões, ao horizonte. ${ }^{15}$ Encontramos aqui a confirmação que a observação de Leonido, para além da distorção de perspectiva introduzida por sua loucura ${ }^{16}$, revelando uma verdade profunda, aquela do desejo de se emancipar da materialidade, ao mesmo tempo que a tensão se manifesta aqui nessa situação paradoxal que é a do suicídio pela rebelião: movimento desesperado que não pode apenas se concretizar pelo sucesso do salto e pela falha da emancipação da gravidade.

A tendência à idealização toma forma do desejo de penetrar no senso íntimo das coisas, de compreender as coisas como idealidade. Temos uma espécie de parábola no imaginário do poeta que deseja tocar o gesto do tocador de harpa sem tocar as mãos, ${ }^{17}$ na imagem também do vagão-cama que permite tocar um vilarejo com a ponta dos dedos ${ }^{18}$. O que é abstrato parece alcançar uma forma de nobreza ${ }^{19}$, pois é o conteúdo da matéria que introduz o fardo de sua gravidade. Ter acesso à ideia das coisas é tocar à sua essência, é conhecer-Ihas em seu ponto nodal; a menos que o desejo do sentido alcance quase seu objetivo, e dê a ilusão, mas ele não o toca nunca verdadeiramente, como é o caso de Capitão Sesto que compreende a voz interior das coisas ${ }^{20}$, mas que não consegue decifrar o que é isso de tão íntimo em si mesmo, seus sonhos.

[...] Sesto foi vítima de um sonho obsessivo, de uma simplicidade indecifrável. Eis o que ele sonhou: ele escrevia uma palavra que não era possível ser lida, e depois ele partiu. [...] Nessa palavra ele explicava porque ele partira, mas ele não conseguia lê-la. Nesta época, louco com esse sonho repetido, o jovem Sesto foi vítima de uma odiosa melancolia. ${ }^{21}$

O sonho parece ser essa parte do homem que tem suas raízes no mistério mesmo da existência, e que parece se alimentar continuamente essa fonte profunda. Mas a verdade que se revela na simplicidade do sonho, essa verdade implícita que não passa sempre pelas palavras, permanece uma

\footnotetext{
${ }_{16}^{15}$ As aves do beato Angelico, cit., p. 81.

${ }^{16} \mathrm{O}$ autor especifica aqui a propósito da loucura, que não é inteiramente tal: "Leonido estava engajado sobre sua via privilegiada da loucura no qual não retornamos, menos porque não podemos do porque não queremos." O pequeno navio, cit., p. 36 (1978, p. 28).

17 Se está fazendo sempre tão tarde, cit., p. 139.

18 Ibidem.

19 "Mas todas as cerimônias são uma estilização, já notei, esta aqui conserva apenas um envelope, o gesto, ela me parece mais nobre, mais abstrata", 0 jogo do reverso, cit., p. 17 (Grifos nossos).

${ }_{20}$ O pequeno navio, cit., p. 188.

${ }^{21}$ Se está fazendo sempre tão tarde, cit., p. 139.
} 
verdade inacessível e ao mesmo tempo bastante próxima, como um dano, mas impossível de ser formulada. Essa espécie de impotência do sujeito, que escreve seu segredo, que diz a causa autêntica de sua partida, mas que não pode decifrar o que ele mesmo escreveu, dá, por sua vez, a ideia de um acesso possível a essa verdade íntima que comporta mesmo a promessa de ser a verdade do mundo enterrada em cada um de nós, e entrega o ser humano à maior ruptura, a uma nostalgia irremediável. O sonho de Sesto que contém a causa de sua partida é portador de um saber escondido: a partida (que pode ser a metáfora da viagem da vida, da passagem do tempo) tem uma causa, mas ela aqui não pode ser dita. O sonho, que em si realiza a leveza que cada um deseja, e pela qual somos emancipados de todas as leis que regem o mundo material - leis da identidade e da não contradição, lei da gravidade, lei da causalidade e da sucessão temporal - se convertem em um fardo que pesa mais ainda que as leis da física cotidiana. $E$ se considerarmos a afinidade da natureza que circula entre a criação poética e o sonho (esse permitindo que, na vida consciente seja introduzida uma parte do mundo onírico, este em uma composição $^{22}$ engenhosamente equilibrada, onde o sonho necessariamente perde sua simplicidade) compreendemos melhor por que Capitão Sesto tinha deixado inacabado seu poema depois dos dois pontos do qual ele parou ${ }^{23}$, como se a explicação final que deveria ser mostrada lá não chegasse a se formular, deixando na incompletude sua composição poética.

É por um empréstimo literário que Tabucchi chega, de maneira mais expressiva, a formular a inexorável busca do senso ligada à aspiração pela idealidade: "Não é um lugar, é um vazio, me refiro à rede. Nessa rede eu persisto em buscar os vazios." ${ }^{24}$ A referência a Montale ${ }^{25}$ aqui é explícita, e ela traduz esse desejo de ver além para encontrar o sentido do aqui na terra, para elucidar o mistério que parece nos envolver, nos encerrar, nos tornar prisioneiros de um Todo que não conhecemos, como se pudéssemos perceber apenas uma parte. Todos os elementos da contingência, todos os objetos da vida material (da vida pela materialidade) regressam a seu contrário: uma idealidade não difusa, uma idealidade dotada de uma lei de organização, de um código, de uma essencialidade que seja ao mesmo tempo a explicação do mundo e da vida humana nesse mundo. E é justamente por esses "vazios", pelas ranhuras sobre a superfície lisa das coisas, pelas asperezas, as inegalidades, que encontramos esse apelo a outra coisa: "era um poeta, ele escreveu um único pequeno livro de poesias, Clepsydra, escute este verso: As rosas selvagens floresceram pelo erro. $E$ tu me perguntou: crês que isso tem algum sentido? ${ }^{26 " . ~ E ́ ~ a l i ~ o n d e ~ a p a r e c e ~ o ~ n o n-s e n s e ~ a p a r e n t e ~ d a ~ s u p e r f i ́ c i e ~ q u e ~}$

\footnotetext{
${ }^{22}$ Composição no setido de compromisso, no sentido onde nos constituímos com.

${ }^{23}$ O pequeno navio, cit., p. 195 (1978, p. 168). Ver também p. 192: "pequena colheita que o liberava do desconhecido".

${ }^{24}$ Se está fazendo sempre tão tarde, cit., p. 15

${ }^{25}$ Ver também a expressão sparute parole (palavra desfigurada), As aves do beato Angelico, Nota, cit., p. 10.

${ }^{26}$ Ibid., p. 75. Notemos que se trata ainda de uma poesia.
} 
se põe a questão do sentido. Pois o non-sense aparente, o "micro"27, nonsense que aparece na trama uniforme da vida cotidiana, abre uma brecha (um vazio na rede) que se abre para um questionamento que põe em causa até a ordem habitual das coisas, aqui o tempo e sua lei habitual (o título da obra citada, Clepsydra, permanece como indicação bem eficaz nessa direção); e o desarranjo que o verso sublinha retoma à questão da ordem temporal, que é a ordem mesma que rege o ser aí indissociável de seu tornar-se que o transforma em ser-para-a-morte. ${ }^{28}$

O real parece submetido a uma dupla lei: a lei da causalidade (a linha causa-efeito) que nós somos capazes de compreender e sobre a qual é modelada nossa razão; aqui, nenhum mistério, a ordem do mundo aparece, então, naturalmente conforme a razão, e nenhuma interrogação tem lugar, pois a resposta se encontra sempre na causa ${ }^{29}$; com essa exceção que alguns fatos podem acontecer sem que saibamos a razão. Essa sequência infinita de "causa-efeito" é, em verdade, apenas um mecanismo no qual a explicação última não é fornecida: de qualquer maneira, é a Causa Primeira que parece fazer falta, pois a lei da causalidade não fornece apenas a "mecânica da superfície ${ }^{30 ", ~ e x p r e s s a ̃ o ~ q u e ~ r e t o m a ~ m a i s ~ u m a ~ v e z ~(a t r a v e ́ s ~ d a ~ p a l a v r a ~}$ superfície) ao mistério subjacente aos fenômenos do mundo.

Outra lei no qual parece submetido o mundo, ou mesmo no qual as vidas humanas parecem submetidas, é uma não-lei, é uma lei de eventos que fogem à lei da causalidade: "Há coisas como essa que chegam sem que saibamos o porquê ${ }^{31}$." A causa, aqui, do que se chega, reside em uma não-causalidade, ou uma causalidade que escapa à razão e retoma, deste modo, à interrogação, ao mistério, ou mesmo à aceitação do non-sense. Mas a aceitação do non-sense existe verdadeiramente? A rigor, podemos dizer de resignação ao non-sense, ou mesmo ainda de esquecimento: passamos da ausência de explicação e pensamos em outra coisa.

No entanto, a interrogação permanece sempre: ela parece ser um fato propriamente humano: "[...] creio que a dimensão da pergunta é uma prerrogativa dos seres que a Natureza não concluiu: e é isso que é evidentemente incompleto que tem o direito de questionar. ${ }^{32 "}$ O ser humano é marcado pela incompletude, podemos mesmo dizer que sua essência é a incompletude, isso que se registra nunca na busca, na pesquisa, no desejo

\footnotetext{
${ }^{27}$ Referimos-nos à "microperspectiva" no qual é a questão apresentada em Voici em O jogo do reverso, cit., p. 130.

${ }_{28}$ Que o transforma em ser-para-a-morte, já que o ser aí é, primeiramente, um ser no tempo.

29 "[...] nós que estamos à procura da mesma lógica: causa efeito, efeito causa, causa efeito, somente para dar um sentido àquilo que é desprovido de sentido." O rio in Se está fazendo sempre tão tarde, cit., p. 28.

30"A carta chegou quase um ano depois, ela explicava tudo com os mínimos detalhes, mas na verdade ela não explicava nada, ela dizia somente como as coisas se passaram, sua mecânica de superfície", O gato de Cheshire in O jogo do reverso e outras histórias, cit., p. 139. Grifos nossos.

${ }^{31} \mathrm{O}$ rio in Se está fazendo sempre tão tarde, cit., p. 25.

${ }^{32}$ As aves do beato Angelico, cit., p. 10.
} 
sempre aberto e jamais saturado do que se dá, então, irremediavelmente, como outro, como inassimilável, como refratário a toda compreensão. É aí que toma lugar a referência à religião na obra de Tabucchi, mas uma referência na qual a solução não é nunca dada ${ }^{33}$ : a religião é mais uma exploração de uma via possível que o lugar de uma resposta sustentável.

Entre a pura contingência e a aspiração a uma ordem fundadora, ao conhecimento de um princípio ou de um princípio que elucida nosso ser-nomundo, se apresenta uma explicação que ultrapassa a simples causalidade sequencial por onde causa e efeito são ligados. É a teoria do caos, pela qual passamos de uma causalidade restrita a uma causalidade generalizada.

[...] agora isso seria muito longo para the explicar e muito complicado. Mas pense numa coisa: que nós estamos em um fractal. Você também faz parte desse fractal, um dos seus movimentos modifica o fractal, caro Senhor Papillon, é porque você deve bater as asas, como é preciso. ${ }^{34}$

Os fractais aqui mencionados têm como origem - ou seja, como ponto de partida - o $\operatorname{caos}^{35}$, a saber, um evento, todo evento puramente fortuito, que aparece no momento mesmo onde aparecem as causas que lhe fizeram nascer. Portanto, um evento radicalmente imprevisível, pois essas causas que o provocam não poderiam ser conhecidas como causas possíveis (talvez fossem elas, mas elas escapariam ao olhar, ou talvez são elas devidas elas mesmas à uma ação humana resultante do único desejo ou do único capricho de um indivíduo). Formulada em termos geométricos, um fractal é a reprodução infinita de um mesmo evento geométrico, da mesma figura; ao infinito e em espiral, ou seja, segundo a cadeia ascendente e descendente dos diferentes graus da realidade; a repetição ao infinito ao mesmo movimento de ar que esse, provocado pelo bater das asas de uma borboleta, pode provocar um tufão em Pequim: isso significa que o que acontece não é realmente fruto do acaso, mas fruto de uma cadeia infinita de causas que podem não ser percebidas como tais, a não ser no momento da catástrofe final que é somente acaso sob o ângulo de nossa ignorância da série de causas que lhe foram produzidas; pois nada chega sem causa(s): é bem mesmo a lei da contingência que se impõe como uma necessidade. Eis, portanto, a formulação de uma ordem substitutiva disso que deveria traduzir a lei do universo: a lei superior mais imanente do encadeamento das causas insignificantes. $E$ cada um de nos interage com o conjunto dessas causas, a todo instante, sem saber e sem querer. É por isso que o personagem que anuncia essa teoria, Senhor

\footnotetext{
33 "Deus somente conhece todas as combinações da existência, mas é a nós somente que ele retorna para escolher nossa combinação entre todas as outras possíveis", O fio do horizonte, Milão, Feltrinelli, 2006 [1986], p. 47.

${ }^{34} \mathrm{O}$ bater das asas de uma borboleta em Nova York pode provocar um tufão em Pequim? In Anjo Negro, cit., p. 89.

35 "Isso não tem importância, é uma teoria dos fractais, ou a rigor, das catástrofes. Você sabe certamente o que são catástrofes, mas talvez não saiba o que são fractais.", ibid.
} 
Consciência, é o guardião de uma Ordem social onde o movimento mínimo de um indivíduo poderia se transformar em uma revolução pela qual se instaurariam uma Ordem radicalmente diferente, pois as revoluções são, elas também, as resultantes dos fractais, como as crises econômicas, por exemplo.

Podemos dizer que os fractais ocupam, de maneira quase parabólica, uma posição central na obra de Tabucchi: do ponto de vista da tradição cultural, os fractais tem seu equivalente no barroco, onde as narrativas em abismo $^{36}$ é tipicamente a reprodução, em cada um dos graus existentes, de uma figura comparável. E sabemos o lugar que ocupa a referência ao mundo barroco no mundo literário de Tabucchi, a referência ao barroco sendo ela mesma uma primeira forma de narrativa em abismo, barroco. Para percorrer bem rapidamente essa questão, indicamos simplesmente que o reverso (rovescio) faz parte, ele mesmo, do campo parabólico dos fractais: ele é a reprodução do mesmo, sobre a forma inversa, narrativa em abismo especular, que tenta recriar uma totalidade a partir da repetição do Mesmo ou de Outro quando é a figura inversa ou o lado oculto deste.

Pertencer a este mesmo universo de abolição do limite, precisamente pelo jogo do retorno especular: em $O$ jogo do reverso, Maria do Carmo mostra o sentido do quatro das Meninas que ela descobre na parte interior da figura: com efeito, com o jogo de espelhos e de pontos de vistas, o limite é abolido entre o espaço representado pelo quadro e o espaço não representado (virtualmente não representado, pois não entra mais no campo de visão do artista) que se encontra abaixo do quadro, e que, geralmente, é o espaço do espectador que contempla o quadro e a cena que lhe é representada; o que permite a introdução da pintura em seu próprio quadro - já que segundo a lógica comum do espaço representado, ele não o é necessariamente e convencionalmente $^{37}$ excluído - é a adoção do ponto de vista dos personagens supostos representados pelo quadro no qual vemos o reverso, os personagens reais (e a confirmação, se podemos dizer, é dada pela sua presença no espelho ao fundo do quadro): o espectador pode então ver que não veem o rei e a rainha, a chegada da família real que vem, de qualquer maneira, perturbar a sessão de pose ${ }^{38}$. Sem entrar em mais detalhes da análise, constatamos que este quadro barroco modifica completamente o sistema de referência entre interior e exterior introduzindo no quadro o que é negado a ser exterior ao que ele representa. O exterior é dado ao mesmo tempo em que o interior, o anverso e o reverso são expostos em um mesmo movimento, como para formar um

\footnotetext{
${ }^{36} \mathrm{~N}$ do T.: "mise en abime", termo cultuado por André Gide para se referir sobre as narrativas que contêm outras narrativas dentro de si.

${ }^{37}$ Convencionalmente porque nos referimos ao pacto da realização (de escritura) e de leitura do quadro.

38 "Enquanto o pintor pintava em seu ateliêa o duplo retrato do rei e da rainha, a infante Margarida desceu até seus parentes, acompanhada de seus seguidores. É o momento familiar e privado que o pintor pinta e coloca diante de seus olhso." Daniel Arasse, Não vemos nada: descrições, Paris, Gallimard, 2003 [Denoël, 2001], Coll. "Folio essais”, 417, p. 215
} 
espaço total, no qual, de qualquer modo, o espectador não repare com facilidade.

Da mesma maneira, Tabucchi consagra uma narrativa, $A$ batalha de São Romano $^{39}$, a um quadro de Paolo Uccelo, no qual ele cita um crítico de arte, Alessandro Parronchi ${ }^{40}$, que nota a presença de um "jogo de perspectiva [...] segundo o qual "é possível situar o espelho de tal maneira que este que olha veja no ar, fora do espelho, a imagem de uma coisa que está fora de seu olho ${ }^{41}$."' A análise da técnica pictural coloca finalmente em evidência o trabalho do artista para modificar substancialmente a relação entre "interior" e "exterior ${ }^{42 ", ~ f a z e n d o ~ e n t r a r ~ n o ~ c a m p o ~ p e r c e p t i v o ~ u m a ~ p a r t e ~ d o ~ e s p a c ̧ o ~ q u e ~}$ normalmente não poderia aparecer. A fusão-confusão interior/exterior corresponde à narrativa em abismo barroca no qual mostramos a relação com a organização fractal, onde a mesma estrutura pertence tanto a um grau superior quanto a um grau inferior (portanto, conteúdos no precedente) do conjunto estabelecido. E como esse modelo é, por sua vez, estendido ao infinito, é a fronteira entre o que é real e o que é imaginário que de repente se abole, um e outro se incluindo reciprocamente em um jogo sem fim, dando lugar a uma interrogação sem resposta possível, como em $A$ vida é um sonho de Calderón de la Barca.

O modelo fractal vai então permitir todos os jogos, as derrotas, os anagramas $^{43}$, ou seja, tudo o que Tabucchi resume sob o termo de equívoco; numerosas coisas que são infrações às regras da lógica aristotélica, em particular àquela da identidade e da não-contradição: neste sistema, uma coisa pode ser por sua vez ela mesma seu contrário, ela pode encontrar sua verdade em seu contrário; vários fenômenos que pertencem não somente à retórica literária mas também e sobretudo à gramática do sonho. Mas não é certamente um azar se esse jogo disputado se encontra em relação com a teoria do caos, dito de outra maneira, dos fractais: e o caos é indistinção, fusão de todas as identidades claramente desenhadas, confusão dos contrários.

Todos esses elementos esparsos, mas convergentes, puderam autorizar uma abordagem girardiana ${ }^{44}$ da obra de Tabucchi: sua estética como toda sua

\footnotetext{
39 In As aves do Beato Angelico.

40 Studi sulla dolce perspeciva, Milão, Martello, 1964.

${ }^{41}$ As aves do Beato Angelico, cit., p. 57.

42 Encontramos a mesma coisa nos quadros de Magritte, como nota o próprio Tabucchi: " [...] como em alguns quadros de Magritte, o exterior parecia atravessar o interior e o anular" Casta Diva in Se está fazendo sempre tão tarde, cit., p. 66.

43 "[...] não foi a toa que ele escreveu um livro sobre o jogo na literatura barroca: anagramas, criptogramas, polissemias, mnemotécnicas, parônimas; era seu campo de pesquisa." Staccia buratta in Anjo Negro, cit., p. 55.

44 Não podemos fazer, neste presente trabalho, citações de textos de René Girard. Retomamos ao leitor que não tem conhecimento aprofundado de seu trabalho apenas algumas obras principais: Le bouc émissaire (o bode expiatório), Paris, Grasset, 1982, em seguida Paris, biblioteca geral francesa, 1986, col. "O livro de bolso. Biblio essais" n 4029 e La violence et le sacré (a violência e o sagrado), Paris, Grasset, 1972, em seguida Paris, O Livro de bolso, 1980, col. "Pluriel" n 8352, para o que concerne sobre o fenômeno da exclusão vitimal; e La route antique des hommes pervers (O caminho antigo dos homens perversos), Paris, Grasset,
} 
visão do mundo contém numerosos elementos de uma crise própria da modernidade, ou seja, de uma crise sem resolução, de uma crise aberta que se perpetua e mantém em permanência seus modos de funcionamento, a saber, a presença simultânea da indistinção e da exclusão: essa última deveria fornecer o elemento de resolução da indistinção, mais precisamente a exclusão não resolve nada, e no lugar de ser o ponto de articulação, de destituição, permitindo a restauração de uma ordem do real claramente estabelecida, parece, ao contrário, que essa destituição se torna a ordem do real ela mesma, se construindo então em um sistema de retomadas ou de contrários equivalentes, ou o caos: essa presença se faz sentir no cerne das coisas, isto é, no seio do próprio sujeito humano. A unicidade da alma $^{45}$ é apenas uma vista do espírito, é apenas uma simplificação que não leva em conta verdadeiramente a realidade. $\mathrm{E}$ até mesmo, levando mais longe a análise, é a distinção do sujeito enquanto tal que não tem sentido: "Conhecer o Ego significa descobrir em nós o que já existe à nós, e descobrir igualmente que não há real diferença entre ser em $\operatorname{mim}$ e a totalidade do universo". Evidentemente, essa frase é colocada na letra que teria sido escrita por um certo Xavier Janata Monroy, interlocutor de Tabucchi nas Mensagens da penumbra ${ }^{46}$, mas tudo isso é bem escrito pelo próprio Tabucchi, pois a pseudoescolha das cartas é somente um expediente visando ao efeito da realidade própria a toda ficção.

Além da presença marcada da indistinção nas obras de Tabucchi, podemos notar que o autor faz referência à hipótese vitimal ao menos duas vezes reprisada em sua obra: em $O$ pequeno navio, Don Giacomino não quer ser sacrificado por linchamento ${ }^{47}$, como vitima expiatória de uma estiagem no qual ele não é, de fato, não mais que ninguém outro, responsável; e em $O$ fio do horizonte, Spino levanta a hipótese de que a morte do qual ele tem de retornar a origem, que ele chama de Kid, poderia ter sido uma vitima sacrificada $^{48}$.

Mas além dessa, há ao longo de toda obra uma série de personagens que carregam signos vitimais, signos distintivos que fazem deles as vítimas

1985, em seguida Paris, Biblioteca geral francesa, 1988, col. "O livro de bolso. Biblio essais" $\mathrm{n}^{\circ}$ 4084 e Des choses cachées depuis la fondaction du monde (As coisas escondidas desde a formação do mundo), Paris, Grasset, 1978 [1989], em seguida Paris, biblioteca geral francesa, 1983, col. "O livro de bolso. Biblio essais" n 4001, para a questão da análise da modernidade.

45 Sobre essa questão, ver Denis Ferraris, em "a alma incontável" (l'âme innombrable) Tabucchi e a vida interior (Tabucchi et la vie intérieure) in "Chroniques Italiennes", Numero 11 (1/2007), Série Web Especial Concours, p. 7-10.

${ }^{46}$ Mensagem da penumbra in As aves do beato angélico, cit., p. 46. Notemos somente que Xavier Janata Monroy é parecido com o personagem de Noturno Indiano Xavier Janata Pinto, e que Janata, em Hindu, significa "público", o que não falta para atenuar o valor da objeção que apresentamos aqui.

47 "Don Giacomino esperava doravante o pior: um acesso de fúria coletiva, talvez um linchamento, ou mesmo uma passagem ao estado mineral por dissecação", O pequeno navio, cit., p. 58 (1978, p. 46).

48 "Talvez o Kid seja a resolução de tudo, mas teria também podido ser também somente uma vítima do sacrifício, ou mesmo algum que seria encontrado num cruzamento do destino" O fio do horizonte, cit., p. 51. 
potenciais ou vitimas designadas: são todos os casos de geminação, todos os duplos e duplicados ${ }^{49}$, as repetições de nomes idênticos. $E$ isso é particularmente verdadeiro para os primeiros textos de Tabucchi onde os Garibaldos tem sempre alguma coisa que afeta seus pés, signo distintivo que encontramos entre os heróis da mitologia como Teseu ou Édipo; são todos os ruivos e ruivas, no qual Capitão Sesto é aqui talvez o único que cumpre melhor sua vocação de vitima se afastando de seu lugar de origem (o barco no qual ele se identifica sendo o símbolo desse afastamento que é necessário compreender igualmente como realização de sua própria exclusão, como autoexclusão) encontrando seu duplo, Ivana, uma menina com cabelos vermelhos, para finalmente satisfazer sua própria condenação.

Outras presenças vitimais são encontradas, como por exemplo, no grupo dos ciganos em A cabeça perdida de Damasceno Monteiro (e sabemos o interesse que Tabucchi alimenta pelos ciganos), acusados erroneamente (portanto efetivamente vitimas inocentes) de uma falha que eles não cometeram (e isso funciona verdadeiramente como bode expiatórios), assim como os judeus, sob a forma de uma presença mais difusa através do nome dos personagens (Pereira é um nome judaico, Spino é um nome que vem diretamente de Espinosa, filósofo de ascendência judia), onde há a rápida referência a determinado açougueiro judeu ${ }^{50}$, em uma estranha reversão da situação onde os judeus são colocados na função de torturadores (sacrificadores de animais, de bodes expiatórios ${ }^{51}$ ).

Em Noturno Indiano, o protagonista da busca é ele mesmo e um outro (a criança adivinha lhe diz claramente: "tu és um outro"), ele é ele mesmo e outro que se lhe procura: a indistinção está no cerne mesmo do sujeito, e a identificação é cindida em duas, ela irrompida, cada um de seus aspectos do Eu (o Eu que procura e o Ego que é procurado, mas que ao fim se revela ser aquele mesmo que continua a ser o sujeito inicial) se encontram em posição de exclusão, de estranhamento em relação à outra parte evasiva do sujeito. 0 outro procurado, Xavier Janata Pinto, possui em seu nome todos os índices da designação vitimal, ao mesmo tempo com esse Janata que quer dizer publico, contendo a indicação de uma identidade impossível de especificar - sem contar que é também isso que poderia liberá-lo de uma exposição - e este

\footnotetext{
${ }^{49}$ Cf. os dois irmãos gêmeos em O pequeno navio a propósito dos quais o primeiro Sesto "fui apreendido de surpresa de não ter apenas uma irmã já que essa memória tão livre teria dividido em duas imagens perfeitamente iguais." Cit., p. 30 (1978, p. 24). Vemos aqui a dupla distinção: aquela constituída pelo fato em si da geminação, e outra constituída pela nãopercepção dessa geminação trazida a uma individualidade simples. A filha de um dos dois (qual? - pois ambos estavam em gestação ao mesmo tempo, um em uma verdadeira gestação e outra em uma gestação psicossomática - "uma pela via genital, outro pela autossugestão" [cit. p. 74, 1978, p. 58] e se confinaram para dar a luz) ele também será marcado por essa distinção, pois ele será chamado de Mariana, nome de cada um de seus irmãos, estimada pela mãe.

${ }^{50}$ Um exemplo entre outros: Afirma Pereira, Milão, Feltrinelli, 2007 [1994], p. 56.

51 Com essa significativa coincidência no francês - como também em italiano com a palavra beccaio - o boucher (açougueiro) é aquele que mata a cabra.
} 
Pinto que pode significar marcado de sardas, onde encontramos um signo já mencionado por outros personagens. Quanto a este Xavier, em italiano Saviero, vemos com um estranho parônimo do palíndromo que fecha $O$ jogo do reverso, servidor-sonhador (Server-rêves) ${ }^{52}$.

O estranhamento ${ }^{53}$, o radicalmente outro que, como sugere René Girard, é o Mesmo, mas não reconhecido, rejeitado na diferença radical, é o que fascina Tabucchi: "as coisas deslocadas exercem sobre mim uma espécie de atração irresistível, como se fosse uma vocação, uma forma de pobre estigma desprovida do sublime. ${ }^{54 "}$ Tabucchi é atraído pela margem, pelo que, como formula Pirandello, está à maneira deste autor, é fouri chiave (fora do tom): tudo que detona, tudo que vem romper com a superfície lisa das coisas, todo que vem introduzir uma fissura no real ou no que tem lugar no real, pois se há uma obra onde o real é propriamente problemático, é justamente na obra de Tabucchi. A frase que citamos retoma aos diferentes aspectos da exclusão vitimaria tal qual se dá na modernidade: o que está de fora, fora do sistema, mas que, ao contrário, não pode ser objeto de nenhuma valorização sacralizadora ("pobre estigma desprovida do sublime"). A fascinação do estigma - e isso não é por acaso se o termo é frequentemente empregado no campo religioso - é ao mesmo temo uma identificação pelo estigma, identificação que é também rejeitada: o maior exemplo disso nos é fornecido pela relação estranha que mantém Spino em $O$ fio do horizonte com o cadáver sem nome e sem história que ele recebe no necrotério: uma busca de identidade (como em Noturno Indiano) mas aqui direcionada não a um ser vivo, embora fantasmagórico, mas a um real fantasma do ser vivo que é um cadáver anônimo. Tabucchu declara, então, seu interesse por tudo que está de fora, não integrado ao sistema, e alguns de seus personagens são eles mesmos excluídos, ou sujeitos que se identificam com os excluídos.

A escrita é, ela própria, uma forma de exclusão: temos uma figuração hiperbólica com Capitão Sesto, um pouco "excêntrica", certamente, mas de uma certa maneira é inerente a essa posição; e se Capitão Sesto é um poeta que nunca escreveu poesia ou que as disseminou ao vento sob a forma de aviões de papel, ainda é este mesmo que conta o conjunto de histórias oferecidas ao leitor, em uma relação difícil de especificar da identidade partilhada com Tabucchi, pois como de outra forma alguém que nunca levou adiante seu projeto de escrita poética poderia levar ao termo a narração de

\footnotetext{
${ }^{52}$ O jogo do reverso e outras histórias, cit., p. 23.

53 O estranhamento é também aquele do sujeito consigo mesmo: "[...] o que eu deveria ser, meu agora presumido se tornou virtual e eu o percebo de longe como em uma longa via invertida, esperando retornar no último momento [...]" O rio in Se está fazendo sempre tão tarde, 2006, p. 36. Nessa passagem não podemos deixar de lembrar de Paulo Post de Pirandello. Cf. De Longe in Escritos Variados: Luigi Pirandello, Saggi, Poesie, Scritti varii, Milão, Mondadori, 1965 [1960], Coll. "Classicos italianos contemporâneos” p. 1064-1075.

${ }^{54}$ Nota in Pequenos equívocos sem importância, cit., p. 7. "As coisas deslocadas" de nossa citação se traduzem por "le cose fuori luogo" (coisas fora do lugar) no texto italiano.
} 
sua falha parcial? A exclusão de Capitão Sesto é parcialmente a mesma de Tabucchi, como é, emblematicamente, aquela de todo criador.

Seria bom colocar um casaco, ir lá embaixo, atravessar a neve e se dirigir em direção ao confessional. É eu, teria dito, eu sou um poeta, toda a poesia é uma falsidade [...] toda escrita é um pecado contra si mesma, você compreende?, Durante toda minha vida eu fui assassinado, me sacrifiquei, pequei contra mim mesmo. ${ }^{55}$

Que a cena se passe em uma igreja não é um fato inofensivo ou fortuito: há certamente a referência a uma sacralidade, no qual testemunham os verbos assassinar e sacrificar de nossa citação, onde o autor é o executor de si mesmo, como se ele possuísse sobre si todos os poderes de exclusão e se fizesse, ao mesmo tempo, o sacrifício e o sacrificador. A essa diferença, exceto o sacrifício de si, se ele "conseguiu" sobre o plano da perda de sua própria vida e de sua própria verdade então temos uma falha sobre o plano do sacrifício e da significação coletiva; o sacrifício de si não é equivalente ao sacrifício de Deus através de seu Filho, em sua própria encarnação, ele é um sacrifício que se abre sobre a repetição dos signos conducentes à exclusão, isto é, aquele que apenas abre um novo ciclo vitimal.

Meu filho, disse o confessor, não te entendo. E então, ele teria gritado mais forte, mas, coisa estranha, quando mais ele gritava menos ele conseguia entender suas palavras, sua voz estava se tornando um ruído atravessado de gritos latejantes, e então, incendiado de paixão, ele começou a cantar. Sim, veja, ele teria ele teria feito exatamente desse jeito, ele começaria a cantar o Requiem de Verdi, e com este réquiem ele teria absolvido todo mundo, os presentes e os ausentes, os vivos e os mortos, e, sobretudo, ele mesmo ${ }^{56}$.

Que o poeta não chegue mais a pronunciar claramente as palavras, que ele não possa mais emitir um gemido, é justamente o retorno dos signos vitimais. A perda da palavra é o que atormenta todo poeta, é uma espécie de vingança suprema do destino, do acaso que se abate sobre o criador e o impede de tomar a palavra ${ }^{57}$. E o mundo que é suscetível de criar pelas palavras o que ele escreve é apenas um mundo fragmentado, no instante do mundo real feito de fractais.

"Mas isso não é um verdadeiro romance", protestei, "é um pedaço pra cá, um pedaço pra lá, não há uma verdadeira

\footnotetext{
${ }_{56}^{55}$ A truta que se mexe entre as pedras me lembram tua vida in Anjo Negro, cit., p. 103.

56 Ibidem.

${ }^{57}$ Cf. Staccia buratta in Anjo Negro, cit., p. 61. "Um escritor expressionista que cobrava sobre as palavras, isso parecia paradoxal, mas Beniamo era assim, sobretudo quando ele estava afetado, então ele se bloqueava sobre a primeira sílaba [...]" Reconhecemos a importância, do ponto de vista da eleição vitimal, da primeira silaba.
} 
história, são apenas fragmentos de uma verdadeira história. $E$ então, não estou escrevendo, eu disse, suponhamos que eu esteja escrevendo." 58

Os elementos de uma composição fractal estão bem presentes aqui: os fragmentos dispersos, que são também quedas, balanças que oferecem a vida - como o cadáver no qual Spino se identificou, que é uma queda ou um resíduo ${ }^{59}$, um fragmento da vida.

O próprio processo de criação é descrito nos termos deste fractal que marca o reino insuperável da contingência: toda parte de um dos acasos do mundo, e as frases pronunciadas pelos seres humanos fazem parte do conjunto de acasos ${ }^{60}$, elas próprias são quedas, decaídas, resíduos ${ }^{61}$ do tempo que passa e resíduo de nós mesmos. As frases se organizam em uma série ${ }^{62}$, em diferentes séries, e elas estão susceptíveis mesmo a se organizar em uma história, em alguma coisa que pareça ter uma coerência, e essa aparência de coerência é apenas, de fato, a homologia da estrutura que ela compartilha com a realidade de nosso mundo, uma realidade de fractais.

Ele pensara que as histórias não começavam, as histórias chegam e não tem começo. Ou ao menos esse começo não se vê, ele fica escondido, pois ele já foi inscrito em outro começo, em outra história, o começo é apenas a continuação de um outro começo. ${ }^{63}$

\footnotetext{
${ }_{58}^{58}$ Noturno indiano, cit., p. 101.

59 “[...] essa morte no qual ele pensava não importava a ninguém, era uma pequena morte no grande ventre do mundo, um cadáver insignificante sem nome e sem história, um detrito da arquitetura das coisas, um resíduo." O fio do horizonte, cit., p. 35. "A arquitetura das coisas" não retoma o fractal, uma ordem fundada sobre o caos, sobre a ausência de centralidade, uma ordem contingente auto-organizada, mas ao mesmo tempo instável, e sucessível a todo instante de se modificar com base na altura, como os elementos climáticos que se organizam sem prevenir um tufão.

${ }^{60}$ Algumas vezes isso pode começar por um nada,uma frase perdida neste vasto mundo cheio de frases, de objetos, de visões [...]" Anywhere out of the world in Pequenos equívocos sem importância, cit., p. 71.

61 "[...] cada palavra flui sobre o chão e voa, salpica, se torna uma estranha estrela circular, mas qual periferia estranha a essa palavra salpicada ao solo, diria um fractal, porque ela foi quebrada, a coitada é uma fração de nós que se quebra como se quebram as ondas sobre a praia, que do vasto mar não são, de qualquer modo, apenas uma fração bem modesta." $A$ circulação do sangue in Se está fazendo sempre tão tarde, cit., p. 57.

62 "[...] cada um forneceu uma pequena tessela, uma pequena pedra que você reuniu, escolheu, colocou no lugar que você sonhou [...] para formar o mosaico que esta noite você verá com seus olhos ávidos, admirado de ver como as coisas acontecem, como uma palavra se ajusta a outra, um evento em outro até criar uma coisa que não existia e agora existe: tua história." Coisas transportadas pelas coisas, impossivel dizer algo in Anjo Negro, cit., p. 14. Uma observação rápida sobre o título dessa narrativa: este sujeito que tem a voz, mas que é impossível dizer, especificar, este sujeito anônimo e no entanto atuante, é essa ordem superior e contingente no momento do fractal, no qual cada um de nós é um pequeno elemento que participa sem saber, e sem saber inclusive em que medida do governo deste Todo frágil, móvel e em contínua reorganização.

${ }^{63}$ Staccia buratta, in Anjo Negro, cit., p. 53. Retomamos à nota precedente para o comentário sobre a relação entre criação literária e fractal.
} 
Após o percurso que tentamos traçar entre as numerosas e ricas sugestões da obra de Tabucchi, podemos constatar um universo literário que insiste sobre os elementos da contingência e que se esforçam para ir em direção a uma explicação, ou pelo menos em direção a uma compreensão que ultrapassa o que acontece (accade), sem devolver a um princípio original participante da Transcendência. À falha do princípio original, parece existir um princípio organizacional por onde a imanência se dá, sem nenhuma intervenção exterior, humana ou outra, uma forma geral no qual a modalidade é a narrativa em abismo, onde se juntam em uma homologia totalmente compatível com um princípio organizacional e também totalmente compatível consigo, a estética barroca e a teoria dos fractais. O lugar do acaso, do acidente (novamente: o que acontece, accade) como aquele do caos é determinante e nós sugerimos uma aproximação com a leitura vitimal proposta por René Girard: a visão do sujeito que podemos expor na obra de Tabucchi, os elementos de indistinção, que são a forma do caos interiorizada, a identificação àquilo que é rejeitado, seja à escória e ao resíduo, colocam o criador em uma posição particular que pode ser aquela da vítima emissária. Mas é bem por esse ângulo da modernidade que queremos abordar as coisas, e o processo de expulsão vitimal, o sacrifício que é também auto-sacrifício do criador não muda nada em relação à situação do caos, pela qual a contingência é soberana do mundo e das vidas que se passam: no máximo o criador pode, no interir do processo de criação, reproduzir em fractal o processo aleatório pelo qual o mundo se organiza e criar, em abismo, um outro mundo homologicamente parecido com o mundo dito real, ficando entendido que no sistema infinito de retomadas, o fictício não é menos real que o que é comumente chamado de real e que a escrita é também a forma, uma das formas de vida.

Gerard VITTORI Université Rennes 2 - Haute Bretagne

VITTORI, G. L'être-là ou la contingence dans l'oeuvre de Tabucchi. Crhoniques Italiennes, vol 13, 2008. Disponível em <http://chroniquesitaliennes.univ-paris3.fr/PDF/web13/Vittori13.pdf> Acesso em 16 de junho de 2016. 